\title{
Translating the Science of Aging into Therapeutic Interventions
}

\author{
James L. Kirkland \\ Robert and Arlene Kogod Center on Aging, Mayo Clinic, Rochester, Minnesota 55905 \\ Correspondence: kirkland.james@mayo.edu
}

Life and health span have been extended in experimental animals using drugs that are potentially translatable into humans. Considerable effort is needed beyond the usual steps in drug development to devise the models, and realistic preclinical and clinical trial strategies are required to advance these agents into clinical application. It will be important to focus on subjects who already have symptoms or are at imminent risk of developing disorders related to fundamental aging processes, to use short-term, clinically relevant outcomes, as opposed to long-term outcomes, such as health span or life span, and to validate endpoint measures so they are acceptable to regulatory agencies. Funding is a roadblock, as is shortage of investigators with combined expertise in the basic biology of aging, clinical geriatrics, and investigational new drug clinical trials. Strategies for developing a path from the bench to the bedside are reviewed for interventions that target fundamental aging mechanisms.

\begin{abstract}
$A$ ging is the largest risk factor for many of the Amajor chronic diseases that account for the bulk of morbidity, mortality, and health costs in developing and developed countries (Alliance for Aging Research 2012; Goldman et al. 2013; Kirkland 2013a,b). Indeed, for most of these conditions, chronological age leads all other known predictors combined. These age-related chronic disorders include atherosclerosis, type 2 diabetes, most cancers, dementias, Parkinson's disease, other neurodegenerative diseases, arthritis, renal dysfunction, blindness, frailty, and sarcopenia, among many others. Key pathogenic mechanisms that predispose to these disorders are shared with mechanisms associated with aging, including chronic, low-grade, nonmicrobial inflammation, cellular senescence, accumulation of damaged macromolecules (DNA,
\end{abstract}

proteins, carbohydrates, and lipids), and stem and progenitor cell dysfunction. These age-associated mechanisms are, in turn, targets of most of the genetic, environmental, and pharmacological interventions that appear to be effective in extending life span in lower mammals. Early indications suggest these interventions may also impact health span, resilience, and multiple age-related disorders in experimental animals.

Based on these observations, the "geroscience hypothesis" has been proposed. By targeting fundamental aging processes, it may be possible to delay, prevent, alleviate, or treat the major age-related chronic disorders as a group, instead of one at a time. Even if a single major chronic disease, such as atherosclerosis, were eradicated, as transformative as such an advance would be, it would only add 2 or 3 years to life

Editors: Fred H. Gage, George M. Martin, and James L. Kirkland

Additional Perspectives on Aging available at www.perspectivesinmedicine.org

Copyright (C) 2016 Cold Spring Harbor Laboratory Press; all rights reserved; doi: 10.1101/cshperspect.a025908

Cite this article as Cold Spring Harb Perspect Med 2015;6:a025908 


\section{J.L. Kirkland}

expectancy (Olshansky et al. 1990; Fried et al. 2009). However, targeting the intersection between fundamental aging mechanisms and processes that lead to chronic diseases could alleviate multiple age-related disorders. For this to be achieved, a great deal of effort will be required to design and conduct the preclinical, clinical proof-of-concept, and formal clinical trials acceptable to regulatory agencies and the medical community. Here, we consider the process of translating drugs that target fundamental aging mechanisms into clinical application, potential indications for which agents that target fundamental aging processes may first be tested, personnel and resources needed to do so, and regulatory and intellectual property issues in developing feasible interventions. Although the path to clinical application of agents that target fundamental aging mechanisms will likely be difficult, the potential to transform health care as we know it is unparalleled.

\section{HEALTH SPAN}

Most members of the public appear to be more interested in an increased health span, the portion of life span during which function is sufficient to maintain independence, productivity, and well-being, rather than extended life span at all costs. Loss of autonomy and control predict mortality (Fry and Debats 2006). The elderly are not resigned to an old age of dysfunction and frailty (Fry 2000). Although study is needed about what the public hopes to gain from biomedical research, it seems there is widespread interest in supporting studies to enhance health span and compress the period of morbidity near the end of life. Increasing emphasis is being placed by the basic biology of the aging community on studying interventions that enhance health span in experimental animals, in addition to studying life span (Kirkland and Peterson 2009; Tatar 2009; Kirkland 2013a). Investigators have started to test if these interventions alleviate chronic diseases, frailty, and resilience in experimental animals.

Limits to health span include disability, frailty, chronic diseases, and, of course, life span (Kirkland 2013a). Disabilities are functional deficits that are consequences of diseases earlier in life, developmental disorders, or accidents. Frailty is a clinical syndrome that involves loss of resilience, with failure to recover from acute problems, such as pneumonia, stroke, influenza, heart attacks, dehydration, or fractures (Fried et al. 2001; Walston et al. 2002, 2006, 2009; Bandeen-Roche et al. 2006; Rockwood et al. 2006; Leng et al. 2007; Kanapuru and Ershler 2009; Qu et al. 2009). Frailty can be diagnosed using clinically validated scales that are moderately sensitive and specific. These scales include combinations of assessments of endurance, weakness, fatigue, weight loss, activity, confusion, and chronic disease and disability burden (Fried et al. 2001; Bandeen-Roche et al. 2006; Lucicesare et al. 2010; Rockwood and Mitnitski 2011). Loss of resilience, or ability to recover after acute insults, can precede overt clinical frailty in the absence of acute, superimposed stresses. Steps have begun to develop tests and markers of frailty for use in experimental animals.

Prevalence of loss of resilience and frailty increases with age (Fried et al. 2001; Walston et al. 2002, 2006, 2009; Bandeen-Roche et al. 2006, 2009; Rockwood et al. 2006; Leng et al. 2007; Kanapuru and Ershler 2009; Qu et al. 2009; Lucicesare et al. 2010; Rockwood and Mitnitski 2011). Frailty predisposes to chronic diseases, dependency, and increased mortality. It is linked to the "geriatric syndromes" of immobility, falling, sarcopenia, cachexia, depression, and confusion, as well as the low grade, nonmicrobial, chronic inflammation implicated in the initiation and progression of multiple chronic diseases. Age-related chronic diseases and frailty individually and in combination contribute to poor responses to treatments, such as chemotherapy, surgery, transplantation, immunization, and rehabilitation. They can initiate a downward spiral of dysfunction that progresses to dependency, institutionalization, and death. Intriguingly, low-grade, chronic inflammation is linked to frailty, dementias, depression, atherosclerosis, cancers, diabetes, and many other age-related diseases as well as advanced chronological age itself, cellular senescence, macromolecular dysregulation, and progenitor cell dysfunction. If and how chronic inflammation 
causally links these processes remains to be ascertained (Ferrucci et al. 1999; Harris et al. 1999; Brown et al. 2001; Pradhan et al. 2001; Walston et al. 2002; Bruunsgaard and Pedersen 2003; Bruunsgaard et al. 2003; Cesari et al. 2003; Spranger et al. 2003; Hu et al. 2004; Pai et al. 2004; Margolis et al. 2005; Tuomisto et al. 2006; Leng et al. 2007; Howren et al. 2009; Kanapuru and Ershler 2009; Srikrishna and Freeze 2009; O'Connor et al. 2010; Schetter et al. 2010; Kirkland 2013a; Tchkonia et al. 2013; Kirkland and Tchkonia 2014).

\section{ARE THERE TRANSLATABLE INTERVENTIONS?}

Aging has increasingly become recognized as a potentially modifiable risk factor for chronic diseases and frailty. Supporting this are the findings, reviewed elsewhere in this series, that (1) maximum life span is extended and age-related diseases can be delayed by several single-gene mutations (Bartke 2011). This suggests that pathways affected by these mutations may be good therapeutic targets. (2) People who live beyond 100, a trait that is sometimes partly heritable, often have delayed onset of age-related diseases and disabilities (Lipton et al. 2010), with compression of morbidity and enhanced health span. (3) Calorie restriction, which increases maximum life span, is linked to delayed onset of chronic diseases in animal models (Anderson and Weindruch 2012). (4) Factors produced by stem cells from young animals enhance cardiac, muscle, and brain repair capacity in the older animals in parabiotic, cross-circulated pairs of young and old mice (Conboy et al. 2005; Lavasani et al. 2012; Katsimpardi et al. 2014; Sinha et al. 2014). (5) Senescent cell accumulation is associated with chronic inflammation, which in turn promotes several age-related chronic diseases and frailty (Tchkonia et al. 2013: Kirkland and Tchkonia 2014). Importantly, removing senescent cells enhances health span in progeroid mice (Baker et al. 2011). Thus, there are multiple indications that fundamental aging mechanisms can be targeted. Indeed, drugs have been discovered that enhance life span and health span in rodents. These in-
Translating Drugs Targeting Aging into the Clinic

clude rapamycin, drugs related to rapamycin (rapalogs), metformin, $17 \alpha$-estradiol, angiotensin converting enzyme inhibitors (and possibly angiotensin receptor blockers), flavonoids related to resveratrol, and aspirin and salsalate (Ferder et al. 1993; Linz et al. 1997, 2000; Basso et al. 2007; Anisimov et al. 2008, 2010, 2011; Strong et al. 2008; Harrison et al. 2009, 2014; Santos et al. 2009; Smith et al. 2010; Lamming et al. 2013; Mercken et al. 2014; Mitchell et al. 2014). Metformin may even enhance survival in older humans (Bannister et al. 2014). Several of these agents also appear to delay cancers, cognitive decline, cardiac dysfunction, and other agerelated diseases and disabilities in several species, including humans (Chiasson et al. 2002; Zeymer et al. 2004; Basso et al. 2005; Dykens et al. 2005; Johnson et al. 2005; Crandall et al. 2006; Hanon et al. 2008; Seibel et al. 2008; Libby et al. 2009; Anfossi et al. 2010; Landman et al. 2010; Li et al. 2010; Tosca et al. 2010; Davies et al. 2011; Huang et al. 2011; Lamanna et al. 2011; Lee et al. 2011; Liu et al. 2011; Monami et al. 2011; Pasternak et al. 2011; Majumder et al. 2012; Roumie et al. 2012; Salani et al. 2012; Tseng 2012; Anisimov and Bartke 2013; Goldfine et al. 2013; Hong et al. 2013; Karnevi et al. 2013; Martin-Montalvo et al. 2013; Quinn et al. 2013; Whittington et al. 2013; Kennedy and Pennypacker 2014; Mannick et al. 2014; Richardson et al. 2014). A pipeline of even more interventions is developing that seem to enhance life span in experimental animals. Many of these interventions are promising, but not yet published. Because drugs that increase life span and health span in mammals now exist, it is plausible that, by targeting fundamental aging mechanisms, clinical interventions might be developed in enough time to influence the health of many people alive today, that could delay, prevent, alleviate, or possibly even partly reverse age-related diseases and disabilities as a group, instead of one at a time.

Targeting the intersection between aging and chronic disease predisposition could circumvent a problem encountered in elucidating the pathogenesis of many of chronic diseases in humans. Many major chronic age-related conditions, including Alzheimer's disease or ath- 


\section{J.L. Kirkland}

erosclerosis, only occur in humans or a few other species. Most age-related chronic diseases are only clinically evident by the time the disease is advanced at the molecular and cellular levels. This makes delineation of etiological mechanisms challenging, because it is obviously not feasible to obtain appropriate tissue samples for study sufficiently early during disease development from human subjects. By targeting the upstream, basic aging mechanisms that predispose to these diseases, these difficulties could be circumvented.

Because several potentially effective interventions that target aging processes have been shown to be effective in increasing life span or health span in experimental animals, there is an opportunity to select those interventions that are more likely to be translatable into clinical applications for humans. Lifestyle interventions, such as caloric restriction, would be particularly challenging, especially in the context of an obesity epidemic. For a pharmacological intervention to be translatable, it would need to have (1) low toxicity plus few side effects, (2) effectiveness by oral administration, (3) once daily, or less frequent dosing, (4) stability, (5) scalability and low manufacturing cost, (6) detectability in blood, and (7) effectiveness if administered in later life or once symptoms have already started to develop. Interventions that need to be started in childhood or early adulthood in asymptomatic subjects with the expectation of health benefit in later life would be difficult to translate into humans. To be acceptable to regulators, these interventions would need to be almost completely devoid of side effects. Furthermore, it would take decades to conduct the studies needed to show efficacy. Such interventions would be of little interest to the pharmaceutical industry because of the time and expense needed for clinical trials and expiration of patents. Similarly, lifestyle interventions that need to be sustained from early life would be difficult to validate in humans or to implement.

\section{INITIAL CLINICAL TRIALS SCENARIOS}

Translating interventions found to be effective in experimental animals into clinical appli- cation can be time-consuming and expensive. Even in fields with an established translational tradition, such as oncology, it can take $<10$ years to complete translation. The process involves preclinical basic studies to determine efficacy, safety, and pharmacokinetics in mammals, usually in at least two species and following the good laboratory practice (GLP) conditions specified by regulatory agencies (Steinmetz and Spack 2009). Clinical outcome measures need to be selected that have been validated clinically, are reproducible, can be measured in a short time frame, are as noninvasive as possible, are accepted by regulatory agencies, and for which there are acceptable animal models. Iterative bench-to-bedside coupled to "reverse translational" bedside-tobench developmental phases are often necessary, particularly for investigational new drugs (INDs). This requires a close partnership between biologists and clinicians with a strong basic biology background.

Although recent progress in developing successful interventions that target fundamental aging mechanisms in rodents has been impressive, the path forward to translation into humans has not yet been fully mapped. Innovative new solutions to the limitations in experimental paradigms, infrastructure, strategies, and personnel are required to translate these interventions into the clinic successfully.

Elderly subjects are generally excluded from clinical trials, particularly those involving INDs. However, early proof-of-concept clinical trials have begun using some of the interventions that have been found to increase life or health span in rodents with drugs already approved for other indications. Rather than determining their effect on life span, which is impractical in humans, these drugs are being used to intervene against particular age-related disorders. For example, a brief course of rapalogs before influenza immunization has been shown to increase immune responses in elderly subjects (Mannick et al. 2014). At least three clinical trials of rapamycin in Alzheimer's disease and another for frailty are underway or about to begin. Resveratrol congeners are being developed to treat type 2 diabetes (Baur et al. 2012). 
At least six potential drug development paradigms can be envisaged, in which drugs that target basic aging processes could be tested in small-scale, relatively short proof-of-concept trials. These include treatment of (1) multiple comorbidities, (2) otherwise fatal conditions, (3) geriatric syndromes such as frailty, (4) decreased resilience, (5) localized diseases related to basic aging processes, and (6) accelerated aging-like states.

\section{MULTIPLE COMORBIDITIES}

Most clinical studies have involved younger subjects with a single disease and excluded subjects with comorbidities. However, multiple age-related chronic diseases frequently occur within the same patients. If the geroscience hypothesis is correct, agents that target fundamental aging mechanisms would be expected to alleviate different age-related chronic diseases within the same older subjects at the same time. Testing whether this occurs will require novel clinical study paradigms. One scenario for initial proof-of-principle trials would be to study effects of interventions in elderly subjects with combinations of two or more of diabetes, atherosclerosis, hypertension, memory impairment, chronic lung disease, renal dysfunction, or other age-related disorders. Outcomes could be surrogate endpoints already accepted by regulatory agencies, such as blood pressure, psychometric tests of cognitive function, fasting glucose, circulating lipids, cardiac function, etc. Endpoints could be combined into a composite score, although this carries the risk that an effective drug may appear less than effective if one of the score components is affected in a direction opposite to that expected. For example, rapamycin might result in improvements in a number of measures of function while also causing insulin resistance (Lamming et al. 2012).

\section{OTHERWISE FATAL CONDITIONS}

Agents that target basic aging processes could be tested in trials for severe or fatal conditions that share pathogenic mechanisms with aging pro- cesses, and for which no effective treatments are available. Among these conditions are certain cancers, cancer predisposition syndromes, idiopathic pulmonary fibrosis, and primary biliary cirrhosis, each of which are associated with cellular senescence (Kirkland and Tchkonia 2014; Calhoun et al. 2015). Caloric restriction affects multiple pathways related to chronological aging. There is evidence that brief caloric restriction might allow use of higher chemotherapy or radiation doses or enhance effectiveness of treatments for cancer (Lee et al. 2012), suggesting that agents that mimic effects of caloric restriction may merit testing for this indication.

\section{GERIATRIC SYNDROMES}

The geriatric syndromes include frailty, sarcopenia, immobility, falls, gait disturbances, mild cognitive impairment, incontinence, and other conditions. As considered above, frailty is a syndrome involving weakness, loss of function, and decreased resilience (Fried et al. 2001; Walston et al. 2002, 2006, 2009; Bandeen-Roche et al. 2006, 2009; Rockwood et al. 2006; Leng et al. 2007; Kanapuru and Ershler 2009; Qu et al. 2009). Frailty can be identified by clinical scales that are somewhat but not perfectly sensitive and specific. These involve measures of weight loss, activity, weakness, fatigue, and numbers of chronic diseases and disabilities (Fried et al. 2001; Walston et al. 2002, 2006, 2009; Bandeen-Roche et al. 2006; Lucicesare et al. 2010; Rockwood and Mitnitski 2011). The prevalence of frailty increases with aging (Fried et al. 2001; Bandeen-Roche et al. 2006, 2009; Rockwood et al. 2006; Leng et al. 2007; Kanapuru and Ershler 2009; Qu et al. 2009; Lucicesare et al. 2010; Rockwood and Mitnitski 2011). Frailty is associated with chronic diseases, loss of independence, high mortality, sarcopenia, immobility, falling, cachexia, depression, confusion, and chronic inflammation.

Subjects with mild or moderate degrees of sarcopenia or frailty would probably be better candidates for initial trials of agents that target basic aging processes than those with severe, likely irreversible frailty. Timed walking distances, strength measurements, inflammation and 
SASP markers, such as circulating IL-6, and pulmonary and renal function tests are among the outcome measures associated with frailty that are predictive of mortality and may soon be recognized by regulatory authorities (Villareal et al. 2011; Tchkonia et al. 2013; McLean et al. 2014).

\section{RESILIENCE}

Resilience, the ability to recover from perturbations, such as surgery, anesthesia, chemotherapy, radiation, a heart attack, fracture, or stroke, diminishes with aging and is associated with concurrent or subsequent clinically overt frailty. Studies of resilience could be scenarios for initial proof-of-principle studies of interventions that target aging processes in relatively short clinical trials. The stressor could be intense, such as time taken to recover from a hip fracture after a fall, or less intense, such as immune response to a routine vaccination. The stressor could be planned, such as chemotherapy, therapeutic radiation, elective surgery, or immunization, or unplanned, for example a heart attack, stroke, or pneumonia. For elective stressors, the candidate drug could be given before the stress occurs and for either elective or unplanned stressors, after the stress-inducing event during recovery.

Some of these types of resilience trials have already been reported. Influenza vaccine responses were demonstrated to be enhanced a couple of weeks after one to three doses of a rapalog (Mannick et al. 2014). Responses to chemotherapyare enhanced and side effects reduced if chemotherapy is preceded by brief caloric restriction (Lee et al. 2012). Effects of interventions that target fundamental aging processes could be tested in multiple clinical trials to determine effects on resilience, such as (1) nausea, appetite, strength, or endurance after chemotherapy; (2) time for recovery after myocardial infarction in older subjects (secondary endpoints could include measures of function, comorbidity, and blood or tissue biomarkers of fundamental aging processes); or (3) time needed for return of function (home vs. nursing home), wound healing, delirium, or discharge disposition after elective surgery.

\section{LOCALIZED DISEASES RELATED TO FUNDAMENTAL AGING PROCESSES}

Some localized disorders involve pathogenic processes similar to those associated with chronological aging. Local administration of agents that target basic aging processes by aerosols, injections, patches, or topical skin solutions could alleviate these conditions. Idiopathic pulmonary fibrosis associated with senescent cell accumulation in the lung (Minagawa et al. 2011; Takasaka et al. 2014) is a sometimes fatal condition without very effective treatment options. Studies with aerosolized senolytic or SASPprotective agents could be considered in patients with this condition if testing in animals, for example, mice with fibrosis induced by aerosolized bleomycin (Moore and Hogaboam 2008), suggest success. Another example is osteoarthritis, an age-related inflammatory condition that can affect multiple joints, which is associated with senescent cell accumulation in joints (Ryu et al. 2014). Osteoarthritis is currently treated with oral analgesics, anti-inflammatories, and intra-articular steroid injections. The oral agents have to be administered frequently, often at least daily. Repeated steroid injections can eventually worsen joint damage. Possibly, systemic or injected drugs that target fundamental aging processes, such as senescence, may have more sustained beneficial and fewer adverse effects than currently used treatments.

\section{CONDITIONS RESEMBLING ACCELERATED AGING}

Several disorders lead to an accelerated aginglike state, such as obesity, diabetes, long-term effects of chemotherapy or radiation, or progeroid syndromes (Kirkland 2013a; Tchkonia et al. 2013; Kirkland and Tchkonia 2014; Ness et al. 2014). It might be possible to alleviate these disorders with agents that target fundamental aging processes. For example, obesity and diabetes are associated with early onset of ageassociated disorders, including frailty, sarcopenia, atherosclerosis, vascular dysfunction, early menopause, cognitive impairment, dementia, 
and cancers (Tchkonia et al. 2010; De Felice and Ferreira 2014; Joost 2014). Survivors of childhood cancers who had been treated with chemotherapy or radiation sometimes develop frailty, sarcopenia, diabetes, cardiac disease, $\operatorname{cog}$ nitive impairment, and unrelated second malignancies by mid-adulthood (Hudson et al. 2013; Ness et al. 2014). Progeroid syndromes have been associated with increased senescent cell burden (Benson et al. 2010). In short-term proof-of-principle studies, effects of candidate drugs on muscle strength, metabolic, cardiovascular, cognitive, or other functional measures could be tested in these subjects.

\section{PRECLINICAL STUDIES}

Experimental animal models are needed that reflect the human disorders, which are potential indications for drugs targeting aging processes. Studies in these models could provide data required so that proof-of-principle human trials can be initiated. For some indications, genetically modified mice or disease-inducing manipulations have been devised. For other indications, there are no models or only ones that are imperfect. Certain genetically modified mice have been developed that resemble human progerias and other syndromes that are caused by single-gene mutations (Baker et al. 2008; Chen et al. 2013; Tchkonia et al. 2013; Eren et al. 2014). In such mice, it is possible to evaluate drug candidates for effectiveness in alleviating aging-like or health-span phenotypes, such as insulin resistance, weakness, decreased endurance, reduced activity, or neurological dysfunction.

Many chronic diseases in humans are multifactorial, polygenic, and clinically manifest in later life. To model these diseases, animals with single-gene mutations have been bred that acquire superficially similar syndromes, but usually in early life. This approach has drawbacks for drug development. Single-gene mutations that lead to AD-like phenotypes in young animals do not fully mimic human $\mathrm{AD}$ in older patients (Shineman et al. 2011). Animals in which dysfunction-provoking mutations can be induced in later life could be better models
Translating Drugs Targeting Aging into the Clinic

for drug development, because an aging tissue microenvironment would exist. It could also be useful to test more than one mutant line, each differing in their disease-inducing mutation, to offset at least partly the problems caused by the strategy of using single-gene mutant mice to model a polygenic disease. More mammalian experimental species beyond mice would help in testing generalizability and meeting regulatory requirements for new chemical entities. More research is required to improve and validate animal models of human age-related diseases.

Manipulations, such as high fat feeding, radiation, pharmacological interventions (e.g., chemotherapy, streptozotocin, PD-inducing agents, inhaled bleomycin or cigarette smoke), cancer xenografts, skin wounding, or surgically induced arthritis can be used in experimental animals to induce age-associated disorders or clinical stresses modeling those in humans. Effects of candidate drugs on a panel of such experimental animal models could provide data useful for deciding about potential clinical applications for each new agent. In some instances, such as $\mathrm{AD}$, rather than using currently available animal models, tests of drugs might be faster and provide better information using human cell culture systems that model disease pathology more closely (Choi et al. 2014). For new chemical entities, new paradigms need to be developed for medicinal chemical optimization and testing toxicology and pharmacokinetics (absorption, distribution, metabolism, and excretion) that use cell culture and animal models in the context of an aging microenvironment.

\section{BIOMARKERS}

Three types of biomarkers are valuable during clinical trials: surrogate endpoint biomarkers, drug activity biomarkers, and biomarkers indicative of molecular and cellular mechanisms. Surrogate endpoint biomarkers are potential primary outcomes of clinical trials that can be substituted for clinical event outcomes. An example would be use of blood pressure as a predictor for risk of stroke, rather than numbers of strokes themselves, as the primary outcome of a clinical trial of a drug intended to reduce stroke 


\section{J.L. Kirkland}

risk. These types of surrogate endpoints can only be accepted by the medical community and regulators after years or decades of clinical studies. These studies need to show that the surrogate endpoint is sufficiently predictive of a clinical outcome and that it can be used in place of that clinical outcome. It would take many decades to validate surrogate biomarkers that predict life span or even health span in humans. Some work has been started to search for and validate surrogate biomarkers for frailty- or age-related disabilities, such as tests of muscle strength or circulating cytokines instead of clinical endpoints, such as time to nursing home admission or death. Although frailty, health span, and resilience biomarkers are some way from being accepted by regulators and first need to be refined in experimental animal and human studies, they are much closer to application than biomarkers predictive of longevity.

The second types of biomarkers are those that can be used to monitor drug delivery, activity, or efficacy, such as assays of blood concentrations of the drug to monitor compliance or tissue mTOR to follow pharmacodynamic activity in the case of rapamycin. These assays can be valuable for optimizing dosing of the drug.

The third types of biomarkers are those that elucidate mechanism of action of the drug in humans. In the case of studies of drugs intended to target fundamental aging processes, a range of parameters related to known aging mechanisms could be assayed to determine whether the drug actually does target aging mechanisms. Assays of parameters to confirm molecular mechanism of action can be informative, but precise information about mechanism of action, although academically interesting, is not always required for drug development. In the cases of many drugs currently used clinically, the molecular mechanism of action was not known before clinical use. Metformin is an example. Its mechanism of action has still not been completely delineated. Knowledge of mechanism of action might help to predict side effects, but in many cases this has not been true. Knowledge gained about molecular mechanisms during human studies may prompt reverse transla- tional laboratory studies that inform future clinical trials, promote discovery of new drug targets and agents, and are helpful in further optimizing preclinical animal models.

\section{CLINICAL TRIALS}

Clinical trials are needed to test whether new interventions are safe, efficacious, and effective. The clinical trial component of drug development is divided into phases. Phase 0 studies are those that determine whether new chemical entities indeed act in humans in the same way as expected from preclinical animal studies, to acquire preliminary information about pharmacokinetics and pharmacodynamics, to identify the most promising lead candidates, or to delineate biodistribution characteristics. Phase 1 trials provide data about metabolism and pharmacologic actions of the drug in human subjects, side effects appearing with escalating doses, and initial evidence of effectiveness. Phase 1 trials can include healthy subjects or patients with the disease being studied. Phase 2 studies are controlled clinical trials to evaluate effectiveness of the candidate drug in subjects with the condition under study and to identify the more common short-term side effects. Some trials combine phases 1 and 2, investigating efficacy and toxicity simultaneously. Phase 3 trials are larger controlled or uncontrolled studies that are designed to generate additional information about risk-benefit relationships and to acquire information needed for drug labeling. Usually, phase 3 trials compare the new drug to drugs already being used to treat that condition. Phase 4 studies are conducted after clinical use has begun. These studies generate additional information about risks, benefits, comparative effectiveness, and optimal use. Phase 4 studies assess effectiveness of the approved drug in the general population and provide information about adverse effects that become apparent once the drug is in widespread use.

Information collected during initial proofof-concept and later phase trials can be used to enable extended follow-up of subjects. This allows evaluation of long-term clinical outcomes and acquisition of information about whether 
the drug delays or prevents other chronic diseases, dysfunction, frailty, or loss of resilience.

\section{TRANSLATION}

Translation refers to research that takes discoveries from the laboratory to the clinic (bench to bedside), reverse translates findings from human studies back to the laboratory so mechanisms can be elucidated or additional applications studied (bedside to bench), or enables adoption into medical practice (bedside to practice). The first, T1, phase of translational research (bench to bedside) brings a basic discovery to initial application. T1 research sometimes involves pilot studies for future larger clinical trials. The T2 phase, bedside to practice, involves ascertaining the value of the drug in large-scale clinical trials. The T3 phase brings evidence-based guidelines developed during phase T2 into clinical practice. The T4 phase involves determining the real-world health effects of the intervention. It often takes more than a decade to progress through these translational steps before new drugs are widely accepted and prescribed.

\section{INVESTIGATORS NEEDED FOR TRANSLATIONAL AGING RESEARCH}

To shepherd drugs that target fundamental aging mechanisms through translation, there will be a need for investigators with an understanding of the basic biology of aging, clinical geriatrics, and conducting clinical trials (Kirkland and Peterson 2009; Kirkland 2013a). However, there is a shortage of such investigators. Few geriatricians have basic biology training or IND experience. Conversely, few basic biologists understand the nuances of clinical geriatrics, how to conduct clinical trials, or regulatory processes, unlike in other areas, such as infectious diseases or oncology. Investigators need to be trained in the basic biology of aging that have a thorough understanding of translational strategies and clinical geriatrics. This could take many years, even if we begin training these investigators now. Until then, teams of basic biologists, clinical geriatricians, and clinical trial
Translating Drugs Targeting Aging into the Clinic

investigators will need to work together to translate agents that target basic aging processes into the clinic. Clinical trial networks could help in advancing the field, perhaps emulating approaches taken by networks in the cancer field.

\section{CONCLUSIONS}

A new era in the basic biology of aging may be beginning, a time in which we can begin to translate findings from the basic biology of aging into a range of clinical applications. Although interventions that delay age-related dysfunction in experimental animals are at hand, development of new clinical trial paradigms with relevant, measureable outcomes accepted by regulators, funding, and personnel with new skills are needed soon. All this must be performed without diverting resources away from the current discovery and mechanistic studies in the aging biology field that are at the start of the pipeline that leads to these important advances.

Some age-related changes involve progenitor depletion, some chronic inflammation, and other extracellular matrix or structural changes (e.g., cataracts, osteoporosis). Different basic aging processes could operate to different extents in different organs and cell types. This suggests that a range of therapeutic strategies may need to be combined to achieve maximal effects, because no one is likely to be a panacea. At least two steps may be needed to alleviate age-related diseases or dysfunction, based on the long-standing principle of first removing bad tissue and then replacing with good tissue. The first step could include targeting senescent cells, the senescence-associated secretory phenotype, inflammation, or damaged macromolecules. The second step to repopulate damaged tissues might involve using agents that restore endogenous progenitor function or transplanting stem cells, differentiated cells, tissues, or organs. Advances are being made in each of these areas, and effective combined approaches may be within reach.

If any or all of the advances in the basic biology of the aging field can be translated into clinical application, it may become feasible to delay, prevent, alleviate, or reverse chronic 


\section{J.L. Kirkland}

age-related diseases and disabilities as a group, instead of targeting them one at a time, and even extend health or life span. If these speculations are realized, health care as we know it would be transformed.

\section{ACKNOWLEDGMENTS}

The author is grateful for advice and ideas shared by members of the Geroscience Network supported by National Institutes of Health (NIH) Grant R24AG044396 as well as support from NIH Grants AG13925, AG41122, and the Noaber, Ellison, and Glenn Foundations.

\section{REFERENCES}

Alliance for Aging Research. 2012. Chronic disease and medical innovation in an aging nation. Silver Book, Washington, DC.

Anderson RM, Weindruch R. 2012. The caloric restriction paradigm: Implications for healthy human aging. Am J Hum Biol 24: 101-106.

Anfossi G, Russo I, Bonomo K, Trovati M. 2010. The cardiovascular effects of metformin: Further reasons to consider an old drug as a cornerstone in the therapy of type 2 diabetes mellitus. Curr Vasc Pharmacol 8: 327337.

Anisimov VN, Bartke A. 2013. The key role of growth hormone-insulin-IGF-1 signaling in aging and cancer. Crit Rev Oncol Hematol 87: 201-223.

Anisimov VN, Berstein LM, Egormin PA, Piskunova TS Popovich IG, Zabezhinski MA, Tyndyk ML, Yurova MV, Kovalenko IG, Poroshina TE, et al. 2008. Metformin slows down aging and extends life span of female SHR mice. Cell Cycle 7: 2769-2773.

Anisimov VN, Egormin PA, Piskunova TS, Popovich IG, Tyndyk ML, Yurova MN, Zabezhinski MA, Anikin IV, Karkach AS, Romanyukha AA. 2010. Metformin extends life span of HER-2/neu transgenic mice and in combination with melatonin inhibits growth of transplantable tumors in vivo. Cell Cycle 9: 188-197.

Anisimov VN, Berstein LM, Popovich IG, Zabezhinski MA, Egormin PA, Piskunova TS, Semenchenko AV, Tyndyk ML, Yurova MN, Kovalenko IG, et al. 2011. If started early in life, metformin treatment increases life span and postpones tumors in female SHR mice. Aging ( $\mathrm{Mi}$ lano) 3: $148-157$.

Baker DJ, Perez-Terzic C, Jin F, Pitel KS, Niederlander NJ, Jeganathan K, Yamada S, Reyes S, Rowe L, Hiddinga HJ, et al. 2008. Opposing roles for p16 ${ }^{\text {Ink4a }}$ and p19 Arf in senescence and ageing caused by BubR1 insufficiency. Nat Cell Biol 10: 825-836.

Baker DJ, Wijshake T, Tchkonia T, LeBrasseur NK, Childs BG, van de Sluis B, Kirkland JL, van Deursen JM. 2011. Clearance of $\mathrm{p} 16^{\mathrm{Ink} 4 \mathrm{a}}$-positive senescent cells delays ageing-associated disorders. Nature 479: 232-236.
Bandeen-Roche K, Xue QL, Ferrucci L, Walston J, Guralnik JM, Chaves P, Zeger SL, Fried LP. 2006. Phenotype of frailty: Characterization in the women's health and aging studies. J Gerontol A Biol Sci Med Sci 61: 262-266.

Bandeen-Roche K, Walston JD, Huang Y, Semba RD, Ferrucci L. 2009. Measuring systemic inflammatory regulation in older adults: Evidence and utility. Rejuvenation Res 12: 403-410.

Bannister CA, Holden SE, Jenkins-Jones S, Morgan CL, Halcox JP, Schernthaner G, Mukherjee J, Currie CJ. 2014. Can people with type 2 diabetes live longer than those without? A comparison of mortality in people initiated with metformin or sulphonylurea monotherapy and matched, non-diabetic controls. Diabetes Obes Metab 16: 1165-1173.

Bartke A. 2011. Single-gene mutations and healthy ageing in mammals. Philos Trans R Soc Lond B Biol Sci 366: 28-34.

Basso N, Paglia N, Stella I, de Cavanagh EM, Ferder L, del Rosario Lores Arnaiz M, Inserra F. 2005. Protective effect of the inhibition of the renin-angiotensin system on aging. Regul Pept 128: 247-252.

Basso N, Cini R, Pietrelli A, Ferder L, Terragno NA, Inserra F. 2007. Protective effect of long-term angiotensin II inhibition. Am J Physiol Heart Circ Physiol 293: H1351H1358.

Baur JA, Ungvari Z, Minor RK, Le Couteur DG, de Cabo R. 2012. Are sirtuins viable targets for improving healthspan and lifespan? Nat Rev Drug Discov 11: 443-461.

Benson EK, Lee SW, Aaronson SA. 2010. Role of progerininduced telomere dysfunction in HGPS premature cellular senescence. J Cell Sci 123: 2605-2612.

Brown DW, Giles WH, Croft JB. 2001. White blood cell count: An independent predictor of coronary heart disease mortality among a national cohort. J Clin Epidemiol 54: 316-322.

Bruunsgaard H, Pedersen BK. 2003. Age-related inflammatory cytokines and disease. Immunol Allergy Clin North Am 23: 15-39.

Bruunsgaard H, Andersen-Ranberg K, Hjelmborg JB, Pedersen BK, Jeune B. 2003. Elevated levels of tumor necrosis factor $\alpha$ and mortality in centenarians. Am J Med 115: $278-283$.

Calhoun C, Shivshankar P, Saker M, Sloane LB, Livi CB, Sharp ZD, Orihuela CJ, Adnot S, White ES, Richardson A, et al. 2015. Senescent cells contribute to the physiological remodeling of aged lungs. J Gerontol A Biol Sci Med Sci doi: 10.1093/gerona/glu241.

Cesari M, Penninx BW, Newman AB, Kritchevsky SB, Nicklas BJ, Sutton-Tyrrell K, Tracy RP, Rubin SM, Harris TB, Pahor M. 2003. Inflammatory markers and cardiovascular disease (The Health, Aging and Body Composition [Health ABC] Study). Am J Cardiol 92: 522-528.

Chen Q, Liu K, Robinson AR, Clauson CL, Blair HC, Robbins PD, Niedernhofer LJ, Ouyang H. 2013. DNA damage drives accelerated bone aging via an NF-кB-dependent mechanism. J Bone Miner Res 28: 1214-1228.

Chiasson JL, Josse RG, Gomis R, Hanefeld M, Karasik A, Laakso M. 2002. Acarbose for prevention of type 2 diabetes mellitus: The STOP-NIDDM randomised trial. Lancet 359: 2072-2077. 
Choi SH, Kim YH, Hebisch M, Sliwinski C, Lee S, D’Avanzo C, Chen H, Hooli B, Asselin C, Muffat J, et al. 2014. A three-dimensional human neural cell culture model of Alzheimer's disease. Nature 515: 274-278.

Conboy IM, Conboy MJ, Wagers AJ, Girma ER, Weissman IL, Rando TA. 2005. Rejuvenation of aged progenitor cells by exposure to a young systemic environment. Nature 433: $760-764$.

Crandall J, Schade D, Ma Y, Fujimoto WY, Barrett-Connor E, Fowler S, Dagogo-Jack S, Andres R. 2006. The influence of age on the effects of lifestyle modification and metformin in prevention of diabetes. J Gerontol A Biol Sci Med Sci 61: 1075-1081.

Davies NM, Kehoe PG, Ben-Shlomo Y, Martin RM. 2011 Associations of anti-hypertensive treatments with Alzheimer's disease, vascular dementia, and other dementias. J Alzheimers Dis 26: 699-708.

De Felice FG, Ferreira ST. 2014. Inflammation, defective insulin signaling, and mitochondrial dysfunction as common molecular denominators connecting type $2 \mathrm{di}-$ abetes to Alzheimer disease. Diabetes 63: 2262-2272.

Dykens JA, Moos WH, Howell N. 2005. Development of $17 \alpha$-estradiol as a neuroprotective therapeutic agent: Rationale and results from a phase I clinical study. Ann NY Acad Sci 1052: 116-135.

Eren M, Boe AE, Murphy SB, Place AT, Nagpal V, MoralesNebreda L, Urich D, Quaggin SE, Budinger GR, Mutlu GM, et al. 2014. PAI-1-regulated extracellular proteolysis governs senescence and survival in Klotho mice. Proc Natl Acad Sci 111: 7090-7095.

Ferder L, Inserra F, Romano L, Ercole L, Pszenny V. 1993. Effects of angiotensin-converting enzyme inhibition on mitochondrial number in the aging mouse. Am J Physiol 265: C15-C18.

Ferrucci L, Harris TB, Guralnik JM, Tracy RP, Corti MC Cohen HJ, Penninx B, Pahor M, Wallace R, Havlik RJ. 1999. Serum IL-6 level and the development of disability in older persons. J Am Geriatr Soc 47: 639-646.

Fried LP, Tangen CM, Walston J, Newman AB, Hirsch C, Gottdiener J, Seeman T, Tracy R, Kop WJ, Burke G, et al. 2001. Frailty in older adults: Evidence for a phenotype. J Gerontol A Biol Sci Med Sci 56: M146-M156

Fried LP, Xue QL, Cappola AR, Ferrucci L, Chaves P, Varadhan R, Guralnik JM, Leng SX, Semba RD, Walston JD, et al. 2009. Nonlinear multisystem physiological dysregulation associated with frailty in older women: Implications for etiology and treatment. J Gerontol A Biol Sci Med Sci 64: 1049-1057.

Fry PS. 2000. Whose quality of life is it anyway? Why not ask seniors to tell us about it? Int J Aging Hum Dev 50: 361 383.

Fry PS, Debats DL. 2006. Sources of life strengths as predictors of late-life mortality and survivorship. Int J Aging Hum Dev 62: 303-334.

Goldfine AB, Fonseca V, Jablonski KA, Chen YD, Tipton L, Staten MA, Shoelson SE. 2013. Salicylate (salsalate) in patients with type 2 diabetes: A randomized trial. Ann Intern Med 159: 1-12.

Goldman DP, Cutler D, Rowe JW, Michaud PC, Sullivan J, Peneva D, Olshansky SJ. 2013. Substantial health and economic returns from delayed aging may warrant a
Translating Drugs Targeting Aging into the Clinic

new focus for medical research. Health Aff (Millwood) 32: $1698-1705$.

Hanon O, Berrou JP, Negre-Pages L, Goch JH, Nadhazi Z Petrella R, Sedefdjian A, Sevenier F, Shlyakhto EV, Pathak A. 2008. Effects of hypertension therapy based on eprosartan on systolic arterial blood pressure and cognitive function: Primary results of the Observational Study on Cognitive Function and Systolic Blood Pressure Reduction Open-Label Study. J Hypertens 26: 1642-1650.

Harris TB, Ferrucci L, Tracy RP, Corti MC, Wacholder S, Ettinger WH Jr, Heimovitz H, Cohen HJ, Wallace R. 1999. Associations of elevated interleukin-6 and C-reactive protein levels with mortality in the elderly. Am J Med 106: $506-512$.

Harrison DE, Strong R, Sharp ZD, Nelson JF, Astle CM, Flurkey K, Nadon NL, Wilkinson JE, Frenkel K, Carter CS, et al. 2009. Rapamycin fed late in life extends lifespan in genetically heterogeneous mice. Nature 460: 392-395.

Harrison DE, Strong R, Allison DB, Ames BN, Astle CM, Atamna H, Fernandez E, Flurkey K, Javors MA, Nadon NL, et al. 2014. Acarbose, 17- $\alpha$-estradiol, and nordihydroguaiaretic acid extend mouse lifespan preferentially in males. Aging Cell 13: 273-282.

Hong J, Zhang Y, Lai S, Lv A, Su Q, Dong Y, Zhou Z, Tang W, Zhao J, Cui L, et al. 2013. Effects of metformin versus glipizide on cardiovascular outcomes in patients with type 2 diabetes and coronary artery disease. Diab Care 36: $1304-1311$.

Howren MB, Lamkin DM, Suls J. 2009. Associations of depression with C-reactive protein, IL-1, and IL-6: A metaanalysis. Psychosom Med 71: 171-186.

Hu FB, Meigs JB, Li TY, Rifai N, Manson JE. 2004. Inflammatory markers and risk of developing type 2 diabetes in women. Diabetes 53: 693-700.

Huang CC, Chan WL, Chen YC, Chen TJ, Lin SJ, Chen JW, Leu HB. 2011. Angiotensin II receptor blockers and risk of cancer in patients with systemic hypertension. Am J Cardiol 107: 1028-1033.

Hudson MM, Ness KK, Gurney JG, Mulrooney DA, Chemaitilly W, Krull KR, Green DM, Armstrong GT, Nottage KA, Jones KE, et al. 2013. Clinical ascertainment of health outcomes among adults treated for childhood cancer. $J$ Am Med Assoc 309: 2371-2381.

Johnson JA, Simpson SH, Toth EL, Majumdar SR. 2005 Reduced cardiovascular morbidity and mortality associated with metformin use in subjects with type 2 diabetes. Diabet Med 22: 497-502.

Joost HG. 2014. Diabetes and cancer: Epidemiology and potential mechanisms. Diab Vasc Dis Res 11: 390-394.

Kanapuru B, Ershler WB. 2009. Inflammation, coagulation, and the pathway to frailty. Am J Med 122: 605-613.

Karnevi E, Said K, Andersson R, Rosendahl AH. 2013. Metformin-mediated growth inhibition involves suppression of the IGF-I receptor signalling pathway in human pancreatic cancer cells. BMC Cancer 13: 235.

Katsimpardi L, Litterman NK, Schein PA, Miller CM, Loffredo FS, Wojtkiewicz GR, Chen JW, Lee RT, Wagers AJ, Rubin LL. 2014. Vascular and neurogenic rejuvenation of the aging mouse brain by young systemic factors. Science 344: $630-634$ 


\section{J.L. Kirkland}

Kennedy BK, Pennypacker JK. 2014. Drugs that modulate aging: The promising yet difficult path ahead. Transl Res 163: $456-465$.

Kirkland JL. 2013a. Translating advances from the basic biology of aging into clinical application. Exp Gerontol 48: $1-5$.

Kirkland JL. 2013b. Inflammation and cellular senescence: Potential contribution to chronic diseases and disabilities with aging. Public Policy Aging Rep 23: 12-15.

Kirkland JL, Peterson C. 2009. Healthspan, translation, and new outcomes for animal studies of aging. J Gerontol A Biol Sci Med Sci 64: 209-212.

Kirkland JL, Tchkonia T. 2014. Clinical strategies and animal models for developing senolytic agents. Exp Gerontol 68: $19-25$.

Lamanna C, Monami M, Marchionni N, Mannucci E. 2011. Effect of metformin on cardiovascular events and mortality: A meta-analysis of randomized clinical trials. $\mathrm{Di}$ abetes Obes Metab 13: 221-228.

Lamming DW, Ye L, Katajisto P, Goncalves MD, Saitoh M, Stevens DM, Davis JG, Salmon AB, Richardson A, Ahima RS, et al. 2012. Rapamycin-induced insulin resistance is mediated by mTORC2 loss and uncoupled from longevity. Science 335: 1638-1643.

Lamming DW, Ye L, Sabatini DM, Baur JA. 2013. Rapalogs and mTOR inhibitors as anti-aging therapeutics. J Clin Invest 123: 980-989.

Landman GW, Kleefstra N, van Hateren KJ, Groenier KH, Gans RO, Bilo HJ. 2010. Metformin associated with lower cancer mortality in type 2 diabetes: ZODIAC-16. Diab Care 33: 322-326.

Lavasani M, Robinson AR, Lu A, Song M, Feduska JM, Ahani B, Tilstra JS, Feldman CH, Robbins PD, Niedernhofer LJ, et al. 2012. Muscle-derived stem/progenitor cell dysfunction limits healthspan and lifespan in a murine progeria model. Nat Commun 3: 608.

Lee MS, Hsu CC, Wahlqvist ML, Tsai HN, Chang YH, Huang YC. 2011. Type 2 diabetes increases and metformin reduces total, colorectal, liver and pancreatic cancer incidences in Taiwanese: A representative population prospective cohort study of 800,000 individuals. $B M C$ Cancer 11: 20.

Lee C, Raffaghello L, Brandhorst S, Safdie FM, Bianchi G, Martin-Montalvo A, Pistoia V, Wei M, Hwang S, Merlino A, et al. 2012. Fasting cycles retard growth of tumors and sensitize a range of cancer cell types to chemotherapy. Sci Transl Med 4: p124ra127.

Leng SX, Xue QL, Tian J, Walston JD, Fried LP. 2007. Inflammation and frailty in older women. J Am Geriatr Soc 55: $864-871$.

Li NC, Lee A, Whitmer RA, Kivipelto M, Lawler E, Kazis LE, Wolozin B. 2010. Use of angiotensin receptor blockers and risk of dementia in a predominantly male population: Prospective cohort analysis. BMJ 340: b5465.

Libby G, Donnelly LA, Donnan PT, Alessi DR, Morris AD, Evans JM. 2009. New users of metformin are at low risk of incident cancer: A cohort study among people with type 2 diabetes. Diab Care 32: 1620-1625.

Linz W, Jessen T, Becker RH, Scholkens BA, Wiemer G. 1997. Long-term ACE inhibition doubles lifespan of hypertensive rats. Circulation 96: 3164-3172.
Linz W, Heitsch H, Scholkens BA, Wiemer G. 2000. Longterm angiotensin II type 1 receptor blockade with fonsartan doubles lifespan of hypertensive rats. Hypertension 35: 908-913.

Lipton RB, Hirsch J, Katz MJ, Wang C, Sanders AE, Verghese J, Barzilai N, Derby CA. 2010. Exceptional parental longevity associated with lower risk of Alzheimer's disease and memory decline. J Am Geriatr Soc 58: 1043-1049.

Liu B, Fan Z, Edgerton SM, Yang X, Lind SE, Thor AD. 2011. Potent anti-proliferative effects of metformin on trastuzumab-resistant breast cancer cells via inhibition of erbB2/IGF-1 receptor interactions. Cell Cycle 10: 29592966.

Lucicesare A, Hubbard RE, Searle SD, Rockwood K. 2010. An index of self-rated health deficits in relation to frailty and adverse outcomes in older adults. Aging Clin Exp Res 22: $255-260$.

Majumder S, Caccamo A, Medina DX, Benavides AD, Javors MA, Kraig E, Strong R, Richardson A, Oddo S. 2012 Lifelong rapamycin administration ameliorates age-dependent cognitive deficits by reducing IL-1 $\beta$ and enhancing NMDA signaling. Aging Cell 11: 326-335.

Mannick JB, Del Giudice G, Lattanzi M, Valiante NM, Praestgaard J, Huang B, Lonetto MA, Maecker HT, Kovarik J, Carson S, et al. 2014. mTOR inhibition improves immune function in the elderly. Sci Transl Med 6: 268ra179.

Margolis KL, Manson JE, Greenland P, Rodabough RJ, Bray PF, Safford M, Grimm RH Jr, Howard BV, Assaf AR, Prentice R. 2005. Leukocyte count as a predictor of cardiovascular events and mortality in postmenopausal women: The Women's Health Initiative Observational Study. Arch Intern Med 165: 500-508.

Martin-Montalvo A, Mercken EM, Mitchell SJ, Palacios HH, Mote PL, Scheibye-Knudsen M, Gomes AP, Ward TM, Minor RK, Blouin MJ, et al. 2013. Metformin improves healthspan and lifespan in mice. Nat Commun 4: 2192.

McLean RR, Shardell MD, Alley DE, Cawthon PM, Fragala MS, Harris TB, Kenny AM, Peters KW, Ferrucci L, Guralnik JM, et al. 2014. Criteria for clinically relevant weakness and low lean mass and their longitudinal association with incident mobility impairment and mortality: The Foundation for the National Institutes of Health (FNIH) Sarcopenia Project. J Gerontol A Biol Sci Med Sci 69: 576-583.

Mercken EM, Mitchell SJ, Martin-Montalvo A, Minor RK, Almeida M, Gomes AP, Scheibye-Knudsen M, Palacios HH, Licata JJ, Zhang Y, et al. 2014. SRT2104 extends survival of male mice on a standard diet and preserves bone and muscle mass. Aging Cell 13: 787-796.

Minagawa S, Araya J, Numata T, Nojiri S, Hara H, Yumino Y, Kawaishi M, Odaka M, Morikawa T, Nishimura SL, et al. 2011. Accelerated epithelial cell senescence in IPF and the inhibitory role of SIRT6 in TGF- $\beta$-induced senescence of human bronchial epithelial cells. Am J Physiol Lung Cell Mol Physiol 300: L391-L401.

Mitchell SJ, Martin-Montalvo A, Mercken EM, Palacios HH, Ward TM, Abulwerdi G, Minor RK, Vlasuk GP, Ellis JL, Sinclair DA, et al. 2014. The SIRT1 activator SRT1720 extends lifespan and improves health of mice fed a standard diet. Cell Rep 6: 836-843. 
Monami M, Colombi C, Balzi D, Dicembrini I, Giannini S, Melani C, Vitale V, Romano D, Barchielli A, Marchionni $\mathrm{N}$, et al. 2011. Metformin and cancer occurrence in insulin-treated type 2 diabetic patients. Diab Care 34: 129131.

Moore BB, Hogaboam CM. 2008. Murine models of pulmonary fibrosis. Am J Physiol Lung Cell Mol Physiol 294: L152-160.

Ness KK, Armstrong GT, Kundu M, Wilson CL, Tchkonia T, Kirkland JL. 2014. Frailty in childhood cancer survivors. Cancer 121: 1540-1547.

O'Connor PM, Lapointe TK, Beck PL, Buret AG. 2010. Mechanisms by which inflammation may increase intestinal cancer risk in inflammatory bowel disease. Inflamm Bowel Dis 16: 1411-1420.

Olshansky SJ, Carnes BA, Cassel C. 1990. In search of Methuselah: Estimating the upper limits to human longevity. Science 250: 634-640.

Pai JK, Pischon T, Ma J, Manson JE, Hankinson SE, Joshipura K, Curhan GC, Rifai N, Cannuscio CC, Stampfer MJ, et al. 2004. Inflammatory markers and the risk of coronary heart disease in men and women. $N$ Engl J Med 351: 2599-2610.

Pasternak B, Svanstrom H, Callreus T, Melbye M, Hviid A. 2011. Use of angiotensin receptor blockers and the risk of cancer. Circulation 123: 1729-1736.

Pradhan AD, Manson JE, Rifai N, Buring JE, Ridker PM. 2001. C-reactive protein, interleukin 6, and risk of developing type 2 diabetes mellitus. J Amer Med Assoc 286: 327-334.

Qu T, Walston JD, Yang H, Fedarko NS, Xue QL, Beamer BA, Ferrucci L, Rose NR, Leng SX. 2009. Upregulated ex vivo expression of stress-responsive inflammatory pathway genes by LPS-challenged $\mathrm{CD} 14^{+}$monocytes in frail older adults. Mech Ageing Dev 130: 161-166.

Quinn BJ, Dallos M, Kitagawa H, Kunnumakkara AB, Memmott RM, Hollander MC, Gills JJ, Dennis PA. 2013. Inhibition of lung tumorigenesis by metformin is associated with decreased plasma IGF-I and diminished receptor tyrosine kinase signaling. Cancer Prev Res (Phila) 6: $801-$ 810.

Richardson A, Galvan V, Lin AL, Oddo S. 2014. How longevity research can lead to therapies for Alzheimer's disease: The rapamycin story. Exp Gerontol 68: 51-58.

Rockwood K, Mitnitski A. 2011. Frailty defined by deficit accumulation and geriatric medicine defined by frailty. Clin Geriatr Med 27: 17-26.

Rockwood K, Mitnitski A, Song X, Steen B, Skoog I. 2006. Long-term risks of death and institutionalization of elderly people in relation to deficit accumulation at age 70 J Am Geriatr Soc 54: 975-979.

Roumie CL, Hung AM, Greevy RA, Grijalva CG, Liu X, Murff HJ, Elasy TA, Griffin MR. 2012. Comparative effectiveness of sulfonylurea and metformin monotherapy on cardiovascular events in type 2 diabetes mellitus: A cohort study. Ann Intern Med 157: 601-610.

Ryu JH, Moua T, Daniels CE, Hartman TE, Yi ES, Utz JP, Limper AH. 2014. Idiopathic pulmonary fibrosis: Evolving concepts. Mayo Clin Proc 89: 1130-1142.

Salani B, Maffioli S, Hamoudane M, Parodi A, Ravera S, Passalacqua M, Alama A, Nhiri M, Cordera R, Maggi
D. 2012. Caveolin-1 is essential for metformin inhibitory effect on IGF1 action in non-small-cell lung cancer cells. FASEB J 26: 788-798.

Santos EL, de Picoli Souza K, da Silva ED, Batista EC, Martins PJ, D'Almeida V, Pesquero JB. 2009. Long term treatment with ACE inhibitor enalapril decreases body weight gain and increases life span in rats. Biochem Pharmacol 78: 951-958.

Schetter AJ, Heegaard NH, Harris CC. 2010. Inflammation and cancer: Interweaving microRNA, free radical, cytokine and p53 pathways. Carcinogenesis 31: 37-49.

Seibel SA, Chou KH, Capp E, Spritzer PM, von Eye Corleta H. 2008. Effect of metformin on IGF-1 and IGFBP-1 levels in obese patients with polycystic ovary syndrome. Eur J Obstet Gynecol Reprod Biol 138: 122-124.

Shineman DW, Basi GS, Bizon JL, Colton CA, Greenberg BD, Hollister BA, Lincecum J, Leblanc GG, Lee LB, Luo F et al. 2011. Accelerating drug discovery for Alzheimer's disease: Best practices for preclinical animal studies. Alzheimers Res Ther 3: 28.

Sinha M, Jang YC, Oh J, Khong D, Wu EY, Manohar R, Miller C, Regalado SG, Loffredo FS, Pancoast JR, et al. 2014. Restoring systemic GDF11 levels reverses age-related dysfunction in mouse skeletal muscle. Science 344: 649-652.

Smith DL Jr, Elam CF Jr, Mattison JA, Lane MA, Roth GS, Ingram DK, Allison DB. 2010. Metformin supplementation and life span in Fischer-344 rats. J Gerontol A Biol Sci Med Sci 65: 468-474.

Spranger J, Kroke A, Mohlig M, Hoffmann K, Bergmann MM, Ristow M, Boeing H, Pfeiffer AF. 2003. Inflammatory cytokines and the risk to develop type 2 diabetes: Results of the prospective population-based European Prospective Investigation into Cancer and Nutrition (EPIC)-Potsdam Study. Diabetes 52: 812-817.

Srikrishna G, Freeze HH. 2009. Endogenous damage-associated molecular pattern molecules at the crossroads of inflammation and cancer. Neoplasia 11: 615-628.

Steinmetz KL, Spack EG. 2009. The basics of preclinical drug development for neurodegenerative disease indications. BMC Neurol 9: pS2.

Strong R, Miller RA, Astle CM, Floyd RA, Flurkey K, Hensley KL, Javors MA, Leeuwenburgh C, Nelson JF, Ongini E. 2008. Nordihydroguaiaretic acid and aspirin increase lifespan of genetically heterogeneous male mice. Aging Cell 7: $641-650$

Takasaka N, Araya J, Hara H, Ito S, Kobayashi K, Kurita Y, Wakui H, Yoshii Y, Yumino Y, Fujii S, et al. 2014. Autophagy induction by SIRT6 through attenuation of insulinlike growth factor signaling is involved in the regulation of human bronchial epithelial cell senescence. J Immunol 192: $958-968$.

Tatar M. 2009. Can we develop genetically tractable models to assess healthspan (rather than life span) in animal models? J Gerontol A Biol Sci Med Sci 64: 161-163.

Tchkonia T, Morbeck DE, von Zglinicki T, van Deursen J, Lustgarten J, Scrable H, Khosla S, Jensen MD, Kirkland JL. 2010. Fat tissue, aging, and cellular senescence. Aging Cell 9: 667-684.

Tchkonia T, Zhu Y, van Deursen J, Campisi J, Kirkland JL. 2013. Cellular senescence and the senescent secretory 


\section{J.L. Kirkland}

phenotype: Therapeutic opportunities. J Clin Invest 123: 966-972.

Tosca L, Rame C, Chabrolle C, Tesseraud S, Dupont J. 2010. Metformin decreases IGF1-induced cell proliferation and protein synthesis through AMP-activated protein kinase in cultured bovine granulosa cells. Reproduction 139: 409-418.

Tseng CH. 2012. Diabetes, metformin use, and colon cancer: A population-based cohort study in Taiwan. Eur J Endocrinol 167: 409-416.

Tuomisto K, Jousilahti P, Sundvall J, Pajunen P, Salomaa V. 2006. C-reactive protein, interleukin-6 and tumor necrosis factor alpha as predictors of incident coronary and cardiovascular events and total mortality. A population-based, prospective study. Thromb Haemost 95: 511-518.

Villareal DT, Chode S, Parimi N, Sinacore DR, Hilton T, Armamento-Villareal R, Napoli N, Qualls C, Shah K. 2011. Weight loss, exercise, or both and physical function in obese older adults. N Engl J Med 364: 1218-1229.

Walston J, McBurnie MA, Newman A, Tracy RP, Kop WJ, Hirsch CH, Gottdiener J, Fried LP. 2002. Frailty and activation of the inflammation and coagulation systems with and without clinical comorbidities: Results from the Cardiovascular Health Study. Arch Intern Med 162: 2333-2341.

Walston J, Hadley E, Ferrucci L, Guralnick JM, Newman AB, Studenski SA, Ershler WB, Harris T, Fried LP. 2006. Research agenda for frailty in older adults: Toward a better understanding of physiology and etiology: Summary from the American Geriatrics Society/ National Institute on Aging research conference on frailty in older adults. $J$ Am Geriatr Soc 54: 991-1001.

Walston JD, Matteini AM, Nievergelt C, Lange LA, Fallin DM, Barzilai N, Ziv E, Pawlikowska L, Kwok P, Cummings SR, et al. 2009. Inflammation and stress-related candidate genes, plasma interleukin-6 levels, and longevity in older adults. Exp Gerontol 44: 350-355.

Whittington HJ, Hall AR, McLaughlin CP, Hausenloy DJ, Yellon DM, Mocanu MM. 2013. Chronic metformin associated cardioprotection against infarction: Not just a glucose lowering phenomenon. Cardiovasc Drugs Ther 27: 5-16.

Zeymer U, Schwarzmaier-D'assie A, Petzinna D, Chiasson JL. 2004. Effect of acarbose treatment on the risk of silent myocardial infarctions in patients with impaired glucose tolerance: Results of the randomised STOP-NIDDM trial electrocardiography substudy. Eur J Cardiovasc Prev Rehabil 11: 412-415. 


\section{$\&_{\mathrm{CSH}}^{\infty} \&$ Cold Spring Harbor

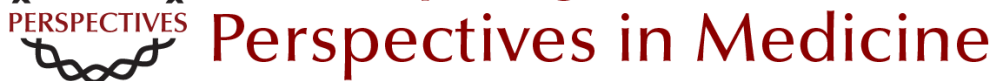

\section{Translating the Science of Aging into Therapeutic Interventions}

James L. Kirkland

Cold Spring Harb Perspect Med 2016; doi: 10.1101/cshperspect.a025908

Subject Collection Aging

Personalized Financial Planning Using Applied Genetics

S. Jay Olshansky, Bradley Willcox, Kirk Ashburn, et al.

Biological Restraints on Indefinite Survival Jan Vijg and Steven N. Austad

The Role of the National Institute on Aging in the Development of the Field of Geroscience

Felipe Sierra and Ronald A. Kohanski

The Funding Channels of Geroscience Stephanie Lederman

Evolutionary Approaches in Aging Research Melissa Emery Thompson

Interventions for Human Frailty: Physical Activity as a Model

Linda P. Fried

How Research on Human Progeroid and Antigeroid Syndromes Can Contribute to the Longevity Dividend Initiative

Fuki M. Hisama, Junko Oshima and George M. Martin

Articulating the Case for the Longevity Dividend S. Jay Olshansky
Funding Life-Extension Research Mehmood Khan

Influence of Aging Science on Global Wealth

Management Michael Hodin

International Gains to Achieving Healthy

Longevity Andrew Scott, Julian Ashwin, Martin Ellison, et al.

From Life Span to Health Span: Declaring

"Victory" in the Pursuit of Human Longevity S. Jay Olshansky

Crowdfunding and Crowdsourcing of Aging

Science Keith Comito

Inhibition of the Mechanistic Target of Rapamycin (mTOR) -Rapamycin and Beyond Dudley W. Lamming

The Emergence of Geroscience as an Interdisciplinary Approach to the Enhancement of Health Span and Life Span

Felipe Sierra

The Economic Promise of Delayed Aging Dana Goldman

For additional articles in this collection, see http://perspectivesinmedicine.cshlp.org/cgi/collection/ 